\title{
On the Determination of Drag Coefficients of Angular Sections Profiles, Isolated or in Group, Using Computational Fluid Dynamics André COSTA ${ }^{\mathrm{a}}$, Fábio PAIVA ${ }^{\mathrm{b}}$, Rui BARROS ${ }^{\mathrm{c},{ }^{*}}$
}

\author{
Faculty of Engineering of the University of Porto, Civil Engng Dept, Structural Division, Portugal \\ acosta.andreivan@gmail.com, ${ }^{b}$ fmp@fe.up.pt, ${ }^{c,}$ rcb@fe.up.pt \\ ${ }^{*}$ Corresponding author
}

Keywords: Drag Coefficients, Aerodynamic, Angular Section Profiles, CFD.

\begin{abstract}
The angular cross section profiles are increasingly used in tall pole structures such as telecommunication towers, transmission towers and wind energy turbine supporting towers. So, this work is based on the aerodynamic study of this type of profiles for three types of considered arrangement of profiles. A Computational Fluid Dynamics (CFD) analysis was performed in the aerodynamic study, permitting to obtain the drag coefficients generated for the various provisions of the profiles arrangements, using the turbulence model RANS k- $\varepsilon$ (Reynolds Averaged Navier-Stokes). The computational modeling was performed using ANSYS FLUENT software on the base of 2D simulations.
\end{abstract}

\section{Introduction}

The objective of this work was part of the master of science dissertation of the first co-author under supervision of the third co-author, consisting in the study of wind flow across sections of a space latticed tower [1].

The computational fluid dynamics, usually referred to as CFD, is the analysis of systems involving fluid flow, heat transfer and associated phenomena such as chemical reactions by means of computer simulations [2]. The physical aspects of any fluid flow are governed by three fundamental principles and a mathematical equation: (a) Principle of mass conservation; (b) Principle of momentum conservation; (c) Equation of state; (d) Principle of energy conservation.

In many applications it is possible to simplify the problems in fluid dynamics. In cases where the flow velocity is much lower than Mach 1, more precisely when the ratio between the flow velocity and the speed of sound is less than 0.3 (according to [3], as it is the case in question), then it can be considered that fluid is incompressible so that it is not necessary the consideration of temperature. Thus, only three principles govern fluid flow: (a) Principle of mass conservation; (b) Principle of momentum conservation; (c) Principle of energy conservation.

The equations corresponding to the principles presented were discretized using the method of finite volumes.

\section{Navier-Stokes Equations}

These basic principles can be expressed in terms of mathematical equations, which usually take the form of partial differential equations [4]. In the case of dynamic equilibrium equations, the equations that will be used in this study are the Navier-Stokes equations (Equations 1-3).

$$
\begin{aligned}
& \frac{\partial u}{\partial t}+u \frac{\partial u}{\partial x}+v \frac{\partial u}{\partial y}+w \frac{\partial u}{\partial z}=-\frac{1}{\rho} \frac{\partial p}{\partial x}+\frac{\mu}{\rho}\left(\frac{\partial^{2} u}{\partial x^{2}}+\frac{\partial^{2} u}{\partial y^{2}}+\frac{\partial^{2} u}{\partial z^{2}}\right) \\
& \frac{\partial v}{\partial t}+u \frac{\partial v}{\partial x}+v \frac{\partial v}{\partial y}+w \frac{\partial v}{\partial z}=-\frac{1}{\rho} \frac{\partial p}{\partial y}+\frac{\mu}{p}\left(\frac{\partial^{2} v}{\partial x^{2}}+\frac{\partial^{2} v}{\partial y^{2}}+\frac{\partial^{2} v}{\partial z^{2}}\right) \\
& \frac{\partial w}{\partial t}+u \frac{\partial w}{\partial x}+v \frac{\partial w}{\partial y}+w \frac{\partial w}{\partial z}=-\frac{1}{p} \frac{\partial p}{\partial z}+\frac{\mu}{p}\left(\frac{\partial^{2} w}{\partial x^{2}}+\frac{\partial^{2} w}{\partial y^{2}}+\frac{\partial^{2} w}{\partial z^{2}}\right)
\end{aligned}
$$


Here it is assumed that: the fluid is a Newtonian fluid, that is, a fluid for which each component of the shear stress is proportional to the velocity gradient in the direction normal to such component, such as occurs with water and air; the viscosity, $\mu$, is constant; and the component of the gravitational force, self-weight, was incorporated into the pressure, $p$, in the corresponding direction [5].

\section{RANS (Reynolds Averaged Navier-Stokes) Turbulence Models}

The turbulence model that will be discussed is a model-based approach k- $\varepsilon$ model that will be used in the modeling of the next chapter; it belongs to the class of models with two equations, called RANS (Reynolds Averaged Navier-Stokes). It is a model that solves the Navier-Stokes equations in a statistical manner and is based on the transport equations for the kinetic energy (parameter $\mathrm{k}$ ) and on the dissipation rate of turbulence (parameter $\varepsilon$ ). It is used for virtually all cases of flow, because of its robustness and a relatively quick resolution and accuracy even in cases with a large range of Reynolds number variation.

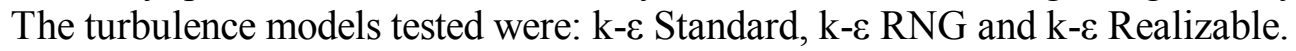

\section{Study of the Flow Around to Angular Cross Section Profiles}

To simulate the fluid flow around angular sections of steel profiles, a type of wind tunnel around the section - called integration domain - should be created. The dimensions used for such domain depend on the flange length of the section and were determined based on several trials where was observed the influence of the interaction of the limits of integration in the final results. The same dimensions were also found to be sufficient so that could be observed all flow phenomena around the section. The dimensions used for the top and bottom section clearances are three times the flange length, and for the left and right lateral spacing are five times the flange length. The section is centered with the integration domain. In Fig. 1 , the respective dimensions and used section are displayed.

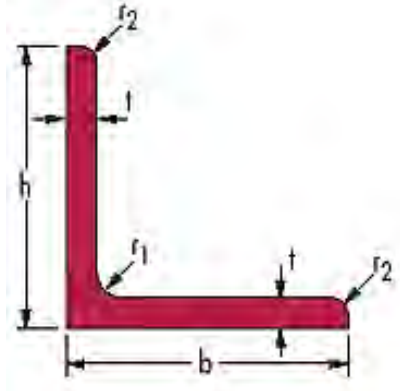

Fig. 1 Cross Section Dimensions

$\left(b=h=100 \mathrm{~mm} ; r_{1}=12 \mathrm{~mm} ; r_{2}=6 \mathrm{~mm} ; \mathrm{t}=10 \mathrm{~mm}\right)$

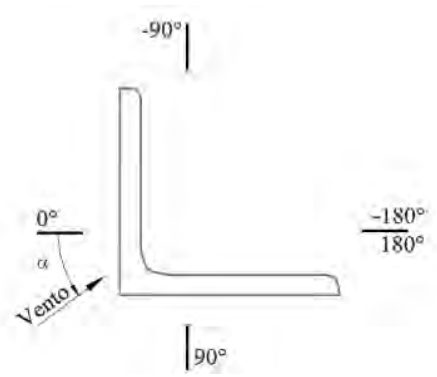

Fig. 2 Convention of Axes and Angles of Incidence of Wind Flow

The mesh was automatically generated using ANSYS meshing feature based on mesh model generation for CFD and adapted to be analyzed in ANSYS Fluent. After the mesh generation, the geometry of the mesh elements in the vicinity of the section and across the integration domain boundaries was observed; any required changes were done applying methodologies of mesh formation, in order to obtain a mesh with better quality and thus able to provide more realistic results.

\section{Flow around Isolated Angular cross Section Profiles}

The first provision studied, was an isolated section for which were performed tests for three angles of incidence (Fig. 2): $0^{\circ}, 45^{\circ}$ and $-180^{\circ}$.

For the tests performed it was verified that for the various turbulence models the drag coefficient $C_{d}$ does not change; therefore for this case study, the turbulence models do not influence the accuracy of the results, as shown in Table 1. Yet at this stage it should be pointed out that the flow analysis in ANSYS Fluent discourages the use of the Standard model for the study of the flow, presenting an error message prompting you to replace the Standard model for the Realizable model.

A comparative analysis of the results of drag coefficients obtained with ANSYS Fluent was done with the values on EN 1991-1-4 [6], British Standard [7] and with experimental results [8], as shown in Table 
2. Analyzing the table, it indicates that the ANSYS Fluent CFD simulations show results very similar with those in the standards EN 1991-1-4 and British Standard, with EN 1991-1-4 being more conservative than the British Standard with respect to the directions $0^{\circ}$ and $-180^{\circ}$. With respect to the results obtained by experimental tests, it appears that the CFD simulations show slightly higher values, and this difference can be justified by the boundary conditions adopted in the CFD analysis.

Tab. 1 Drag Coefficient

\begin{tabular}{|c|c|c|c|c|}
\hline & & \multicolumn{3}{|c|}{$C d$} \\
\hline & Incidence angles & $0^{\circ}$ & $45^{\circ}$ & $-180^{\circ}$ \\
\hline \multirow{3}{*}{ 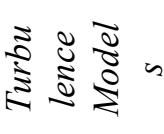 } & Standard & 2,04 & 1,55 & $-2,04$ \\
\hline & $R N G$ & 2,04 & 1,55 & $-2,04$ \\
\hline & Realizable & 2,04 & 1,55 & $-2,04$ \\
\hline
\end{tabular}

Tab. 2 Comparative Values of Drag Coefficients

\begin{tabular}{cccc}
\cline { 2 - 4 } & \multicolumn{3}{c}{$C_{d}$} \\
\hline Incidence angles & $0^{\circ}$ & $45^{\circ}$ & $-180^{\circ}$ \\
\hline EN 1991-1-4 & 2,10 & - & $-2,10$ \\
\hline British Standard & 2,00 & 1,40 & $-1,80$ \\
\hline Experimental tests & 1,80 & 1,47 & $-1,39$ \\
\hline CFD analysis & 2,04 & 1,55 & $-2,04$ \\
\hline
\end{tabular}

In order to understand how wind will flow around the profile angular section, noting the places where wind flow create negative pressures and locations where pressures are highest, the streamlines obtained from CFD analysis by ANSYS Fluent (for the three angles of incidence studied) as a function of flow velocity, are presented in Fig. 3 .

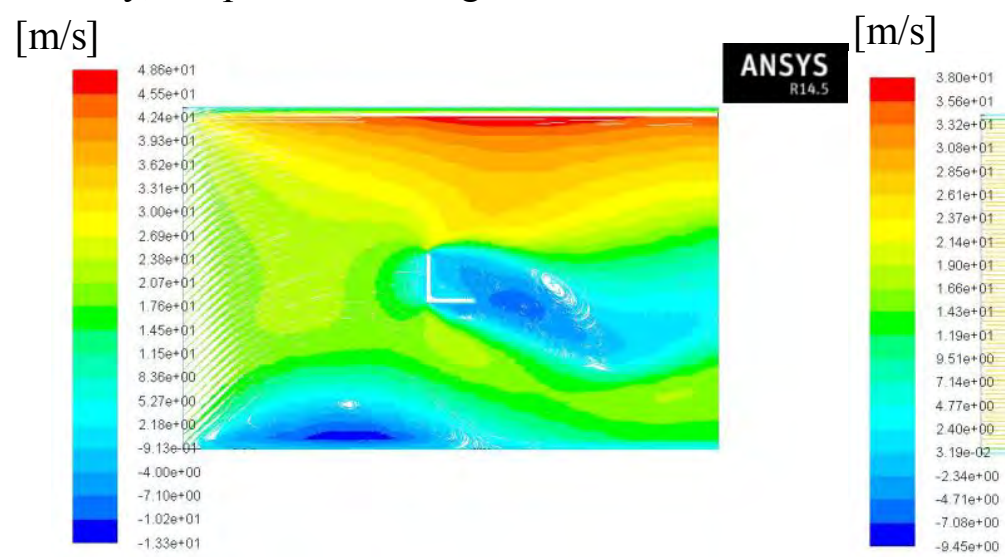

(a)

(b)

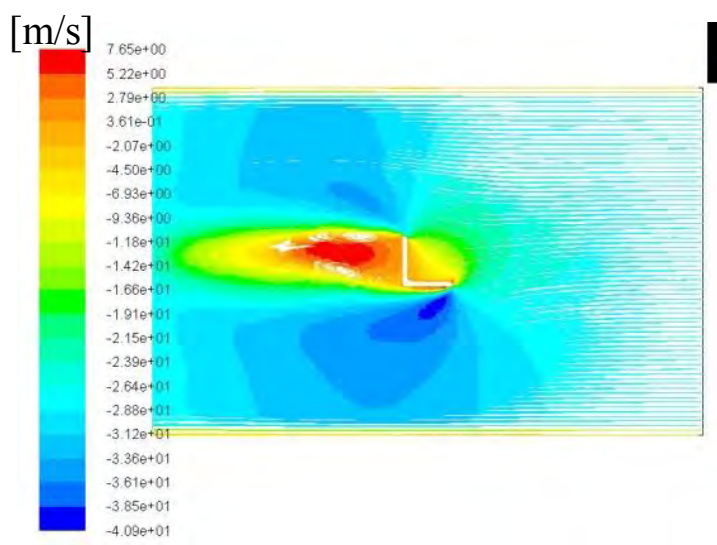

ANSYS

(c)

Fig. 3 Flow around the Section for Angles of Incidence $0^{\circ}(\mathrm{a}), 45^{\circ}(\mathrm{b})$ and $-180^{\circ}$ (c), respectively 


\section{Study of the Interaction between Two Angular cross Sections}

This study examined the effect of shading (or shielding) that a section causes on another in the same stream plane (Fig. 4). It allows determining the distance for which this effect ceases. The drag coefficients $C_{d}$ are determined for each spacing ratio between profiles. The study was initiated for a distance between sections $(c)$ equal to the length of the section flange $(d)$. As the spacing ratio $(c / d)$ increases, it is expected that the shadowing effect decreases, tending the drag coefficient to a value as if the profile was isolated. So, there is a certain spacing ratio for which the drag coefficient of the shielded profile is equal to that of an isolated profile. Therefore this iterative study ends when the equality of drag coefficients occurs. The flow was simulated using the k- $\varepsilon$ turbulence models. Table 3 presents the drag coefficients obtained based on the spacing ratio and for each turbulence model.

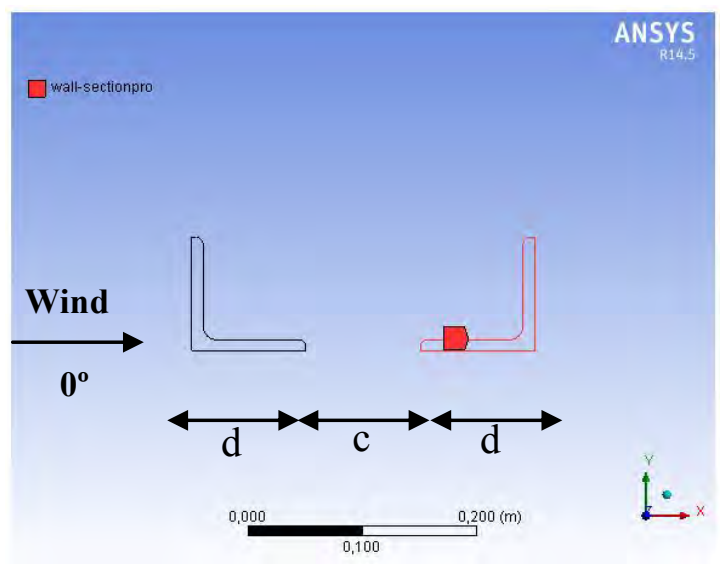

Fig. 4 Indication of the Shielded Profile Section and of Angle of Wind Incidence

Tab. 3 Drag Coefficients Depending on the Spacing Ratio $(c / d)$

\begin{tabular}{|c|c|c|c|c|}
\hline & & \multicolumn{3}{|c|}{$C d$} \\
\hline & $\begin{array}{c}\text { Turbulence } \\
\text { Models }\end{array}$ & Standard & $R N G$ & Realizable \\
\hline \multirow{7}{*}{$\frac{\partial}{u}$} & 1 & 1,73 & 1,73 & 1,73 \\
\hline & 2 & 1,86 & 1,86 & 1,86 \\
\hline & 4 & 1,87 & 1,87 & 1,87 \\
\hline & 6 & 1,87 & 1,87 & 1,87 \\
\hline & 8 & 1,79 & 1,79 & 1,79 \\
\hline & 10 & 1,84 & 1,84 & 1,84 \\
\hline & 12 & 1,97 & 1,97 & 1,97 \\
\hline
\end{tabular}

As was already concluded in the analysis of wind flow around the isolated profile sections, also here there is no influence of the turbulence models on the results of the interactions between the upstream section profile and the shielded section profile.

Analyzing Table 3, notice that for a spacing between profiles corresponding to twelve times the length of the section flange there is a drag coefficient of 1,97 which is a reduction of approximately $4 \%$ compared to the drag coefficient of the isolated section profile; for this value, it is assumed that the shadow or shielding effect ceases to exist. Notice also that the maximum value of reduction of the drag coefficient by shielding was approximately $18 \%$, and it corresponds to a unit spacing ratio.

Studies conducted on the interaction of sections in the same plane [8], with the same orientation of the sections presented in this study, indicate maximum reductions in drag coefficient by $25 \%$ and decreasing as spacing ratio increases. Such studies also show that for spacing ratios between 10 to 15 , the shielded protected section profile have drag coefficients as if the section was isolated; a fact that was also verified by CFD analysis using ANSYS Fluent.

In Fig. 5 is presented the evolution of the streamlines for spacing ratios of $\mathrm{c} / \mathrm{d}=1, \mathrm{c} / \mathrm{d}=4, \mathrm{c} / \mathrm{d}=8$ and $\mathrm{c} / \mathrm{d}=12$. It can be observed that for $\mathrm{c} / \mathrm{d}=12$ the streamlines and the velocity distribution stabilize before reaching the shielded profile section, leaving this section as if it was isolated. 


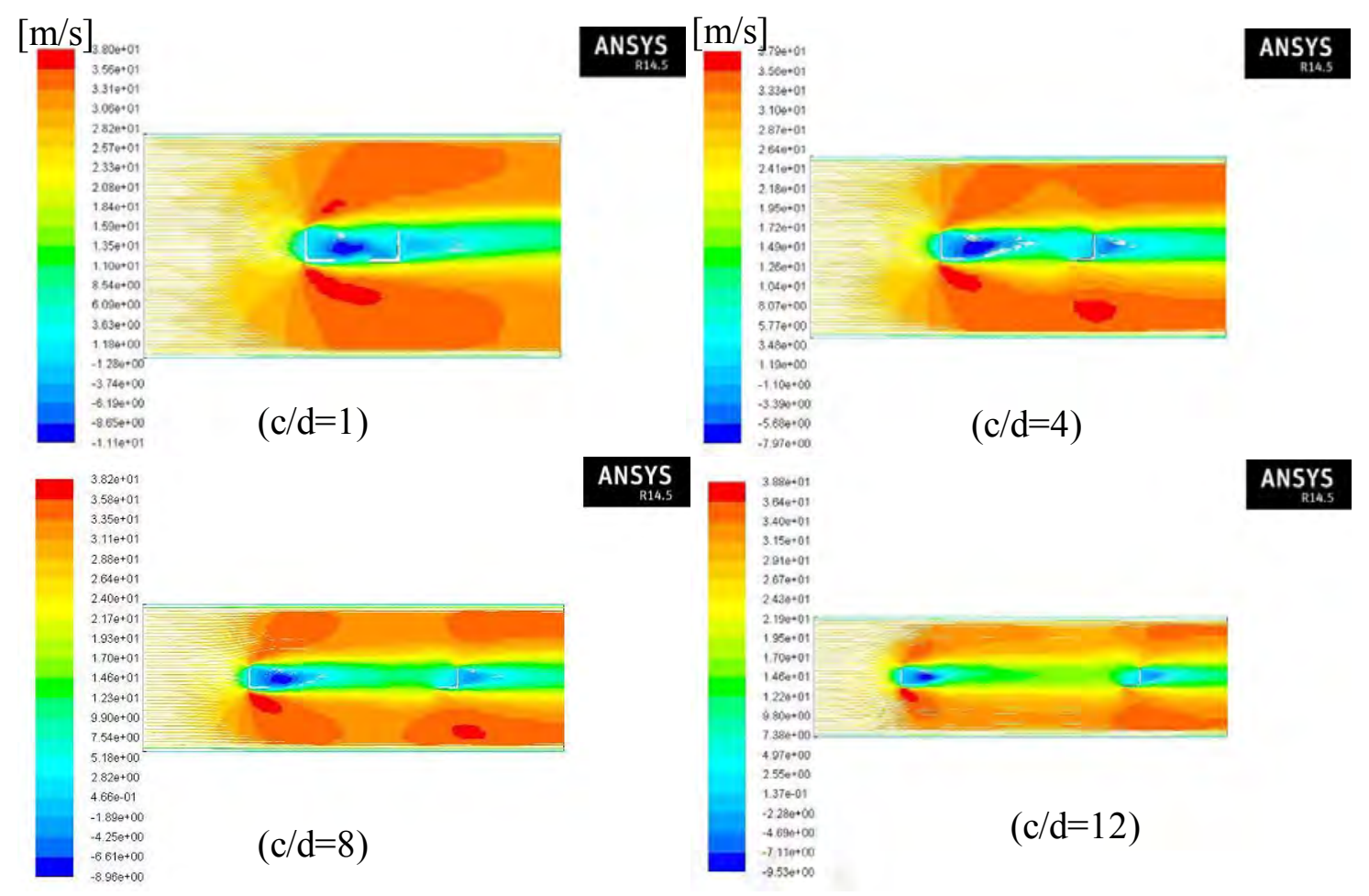

Fig. 5 Flow around the Sections for Various Spacing and for Wind Flow at $0^{\circ}$ direction

\section{Flow around a Composite Section of Angular Profiles of a Lattice Structure}

The flow around a composite section of angular profiles of a lattice structure was also studied, which simulate the base of a square lattice tower framework. To simplify the case study only the main sections of the structure without the bracing elements was modeled, as seen in Fig. 6. The spacing between sections will be fixed, five times the length of the section flange, not analyzing the interaction effect. From this study results the determination of the drag coefficient, generated for the angle of wind flow incidence of $0^{\circ}$, which can be compared with the values given in EN 1991-1-4 [6].

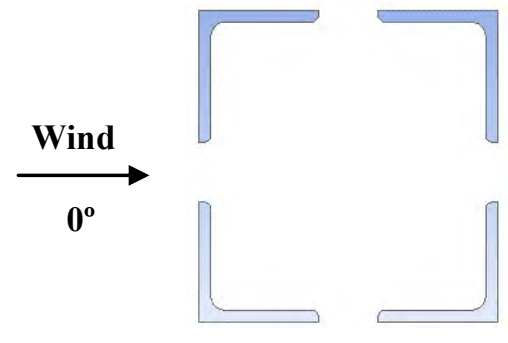

Fig. 6 Disposition of Angular Sections

The results of the drag coefficients based upon the performed simulations are shown in Table 4, as a function of turbulence models used.

Tab. 4 Drag Coefficients for a Composite Section of Angular Profiles

\begin{tabular}{|c|c|c|}
\hline & & $C_{d}$ \\
\hline & Incidence angles & $0^{\circ}$ \\
\hline \multirow{3}{*}{ 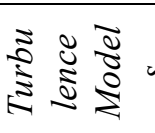 } & Standard & 3,94 \\
\hline & $R N G$ & 3,94 \\
\hline & Realizable & 3,94 \\
\hline
\end{tabular}

Again, analyzing the results, it appears that the turbulence models do not influence the final results. The object of this study was to compare the values of the drag coefficient obtained by CFD analysis (that is 3.94), with the design values for this case as presented in the norm EN 1991-1-4 [6] which indicates a drag coefficient of 2.7 ; the former is about $45 \%$ higher than the latter. For this case study, CFD analysis 
generated better than expected results; this difference can be explained by the sensitivity of the analysis to the effects of interaction between the sections, and also by the internal recirculation inherent to exist between them (Fig. 7). Such phenomena cause a valve effect, thereby increasing the force generated by the wind flow and hence the drag coefficient.

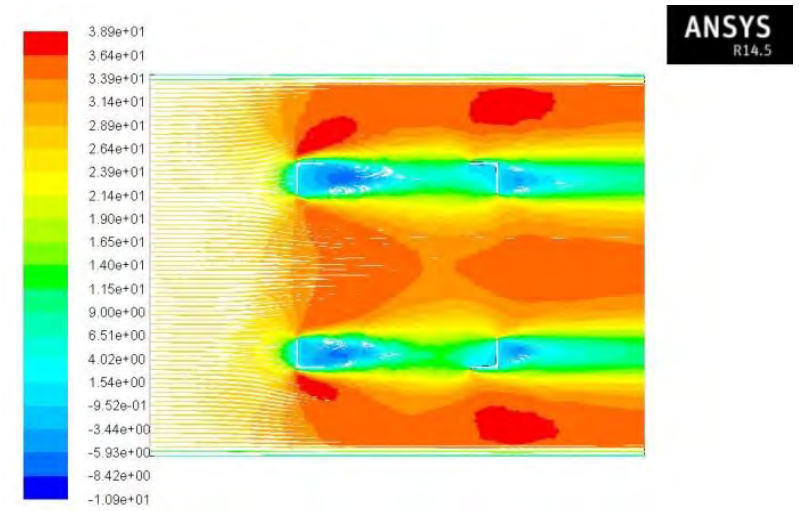

Fig. 7 Streamlines around the Composite Section of Angular Section Profiles

\section{Conclusion}

As a general conclusion of this work it can be stated that the CFD analysis using ANSYS Fluent proved to be important in the analysis of wind flows, with streamlines of high precision with which can be observed the various phenomena that occur in the contiguous areas of the sections and thus locate hotspots where high pressures are generated. This study also proved effective in determining the drag coefficients generated, and ascertaining the regulatory values present in the various design codes. Only the case of the cross section of a lattice tower has led to significant differences that were thoroughly justified.

\section{Acknowledgement}

The authors acknowledge the support from the project "VHSSPOLES - Very High Strength Steel Poles" (Faculty of Engineering of the University of Porto, reference 21518).

\section{References}

[1]A.I.A. Costa, Estudo do escoamento do vento através de uma torre treliçada espacial, Master of Science dissertation (in Portuguese), Faculty of Engineering of the University of Porto, Porto - Portugal, 2014.

[2]H.K. Versteeg and W. Malalasekera, An introduction to computational fluid dynamics: the finite volume method, Pearson Education, 2007.

[3]J.H. Ferziger and M. Peric, Computational methods for fluid dynamics, Vol.3, Springer, Berlin, 2002.

[4]J. Novais-Barbosa, Mecânica de Fluidos e Hidráulica Geral, Vol.1, Porto Editora, Porto, 1986.

[5]M.B. Abbot and D.R. Basco, Computational fluid dynamics - An introduction for engineers, NASA STI/Recon Technical Report A, 1989.

[6]Instituto Português da Qualidade, Eurocódigo 1 - ações em estruturas Parte 1-4 ações gerais. Ação do vento, NP EN 1991-1-4:2010/A1:2010, Caparica, 2010.

[7]British Standard, Code of basic data for the design of buildings, Loading, Wind loads, 2003.

[8]T. Klein, Estudo em túnel de vento das características aerodinâmicas de torres metálicas treliçadas, Dissertação de Mestrado, Universidade Federal do Rio Grande do Sul, Brasil, 2004. 